\title{
Ética marxista en el mundo globalizado
}

Autor: Raphael Silva Rodrigues

DOl: https://doi.org/10.25058/1794600X.1800 


\section{ÉTICA MARXISTA EN EL MUNDO GLOBALIZADO*}

Raphael Silva Rodrigues ${ }^{a}$

raphaelsilva.bh@gmail.com

Fecha de recepción: 9 de abril de 2020 Fecha de aprobación: 1 de junio de 2020

DOI: http://doi.org/10.25058/1794600X.1799

Para citar esta reseña:

Rodrigues Silva, R. (2020). Ética marxista en el mundo globalizado. Revisto Misión Jurídica, 13, (19). 308-312.

La crítica del marxismo al capitalismo tiene un significado moral, aunque ciertamente no se reduzca a él, pues el capitalismo es criticable también por no satisfacer las necesidades vitales de la inmensa mayoría de la humanidad. En verdad, este sistema no consiguió ofrecer los bienes materiales y sociales y para llevar, no a la "buena vida" de la cual disfruta la minoría privilegiada, sino para vivir en las condiciones humanas indispensables, en lo que se refiere a la alimentación, vivienda, salud, seguridad o protección social. Sin embargo, el capitalismo de ayer y de hoy puede y debe ser criticado por la profunda desigualdad en el acceso a la riqueza social y a las injusticias que derivan de ella; por la negación o limitación de las libertades individuales y colectivas o por su reducción - cuando las reconoce - a un plan retórico o formal; por su tratamiento de los hombres - en la producción y en el consumo - como simple medios o instrumentos. Todo eso entraña la asfixia o limitación de los valores morales correspondientes: la igualdad, la justicia, la libertad y la dignidad humana. (Vázquez, 2006: ).

\footnotetext{
* Nota científica construida con base en la ponencia presentada en 3 mayo de 2018, en lo IV SEMINARIO INTERNACIONAL DE TEORÍA JURIDICA Y FILOSOFÍA DE DERECHO - "Bicentenario del Natalicio de Karl Marx: Actualidad y perspectivas", promovido por la Faculdad de Derecho de la Universidad Colegio Mayor de Cudinarmarca, Bogotá, Colombia. El autor agradece sinceramente tan importante invitación a la prestigiosa Casa de Estudios UNICOLMAYOR, así como a la Facultad de Derecho y su oficina de internacionalización la invitación a este evento.

a. Doctorado en Derecho por la UFMG y por la UAJFK. Maestría en Derecho por la UFMG. Especialista en Derecho Tributario por la PUC/MG. Profesor Universitario en diversos Cursos de Graduación y de PostGrado Lato Sensu. Miembro Colaborador de la Comisión de Derecho Tributario de la OAB/MG. Miembro del Consejo Técnico y Editorial del Instituto Minero de Estudios Tributarios y Previsionales (IMETPrev). Miembro del Consejo Editorial de la Revista Fórum de Derecho Tributario (RFDT), Parecerista (Double Blind Peer Review) de RFDT, Parecerista de la Revista Misión Jurídica, de la Facultad de Derecho de la Universidad Colegio Mayor de Cundinamarca, Bogotá, Colombia. Miembro integrante de Bancas Examinadoras de Concursos Públicos. Autor y coautor de libros, capítulos de libros y artículos de revistas científicas. Abogado. raphaelsilva.bh@gmail.com
} 


\section{LA ÉTICA MARXISTA}

A lo largo de la historia del pensamiento occidental, entre las tantas preocupaciones de investigar y dar respuestas a los diversos problemas que se refieren al ser, pensar y actuar humano, se encuentra la reflexión de naturaleza ética. La ética se constituye como una reflexión filosófica de un comportamiento humano específico, el comportamiento moral, que comúnmente se sintetiza por la acción humana libre, consciente, responsable.

Tales cuestiones han sido reflejadas por varios pensadores y sistematizadas en teorías éticas, muchas veces expresas en grandes tratados, que influencian hasta hoy el pensamiento y las prácticas humanas. Entre tales pensadores, citamos a Platón, Aristóteles, Agostinho, Tomás de Aquino, Descartes, Spinoza, Hume, Kant, Kierkegaard, Nietzsche, Stuart Mill, Max Weber, Freud y Foucault.

Así, partimos de la constatación de que la ética es una cuestión presente en la historia del pensamiento filosófico, que un gran número de pensadores y escuelas filosóficas hicieron reflexiones y produjeron teorías éticas, que pueden ser sintetizadas en dos grandes corrientes teóricas, las éticas teleológicas y las éticas deontológicas. Las éticas teleológicas atribuyen la función de criterio supremo al fin último para el cual se dirige el hombre en sus acciones, y están presentes en el hedonismo, en el utilitarismo, en el eudemonismo, en las éticas de los valores, por ejemplo. Las éticas deontológicas atribuyen el papel de criterio supremo a las leyes y a los deberes, como el estoicismo, el formalismo kantiano, por ejemplo.

Ante esta constatación histórica, el autor intentará responder en este escrito ¿cuál es el lugar de la ética en Marx?, más aún, ¿hay fundamentos éticos en el pensamiento de Marx? Si los hay, ¿cuáles son?, ¿cuál es su lugar en la obra de Marx? En el desafío de responder a esta cuestión, se investigaron las principales fuentes del pensamiento marxista, es decir, los textos de Marx. Y, por otro lado se indagó, en la tradición marxista, qué autores hacen reflexión sobre la cuestión de la ética.

Sin embargo, sin poder analizar exhaustivamente todos los textos de Marx, se buscó, en el núcleo de la tradición marxista, la preocupación ética en el pensamiento de Marx. Se descubrió que, a lo largo de la tradición del pensamiento marxista, muchos pensadores se dispusieron a discutir y produjeron textos sobre ética. Entre ellos: Lenin, Agnes Heller, Adolfo Sánchez Vásquez, Henri Lefebvre, Sérgio Lessa, Dermeval Saviani, Mihailo Markovic y István Mészaros. Por otro lado, autores como Anton Shiskhin organizaron antologías de textos sobre ética y marxismo.

La ética marxista se fundamenta en la concepción de hombre como ser concreto, social e histórico, en una ontología inmanentista, en la visión materialista de la historia, en las determinaciones de la existencia social de los hombres bajo relaciones sociales y económicas determinadas, en una sociedad dividida en clases.

La ética marxista no es normativa, ni prescriptiva. Su base teórica y política es la historia. A la luz del desarrollo histórico, ella trata de explicar por qué en determinada época histórica predominan principios y normas de comportamiento y en virtud de qué razón, éstas dan lugar a otros principios.

Marx no dice ni hace una descripción de cómo será la historia futura, sólo muestra el mecanismo efectivo de su construcción, hecha por hombres, conscientemente, en la búsqueda de sus objetivos. La historia es hecha por las acciones humanas, es continuidad y ruptura. La humanidad no elige las circunstancias y la base material sobre la cual construye alternativas de su desarrollo, pero puede actuar sobre esa base y cambiarla.

Eso significa que el marxismo tiene sueños, utopías, de lo que es posible que ocurra, una vez abolida la explotación del hombre por el hombre. Tener conocimiento de la realidad efectiva, tener consciencia de las posibilidades de su superación, utilizarse de los medios adecuados para ese intento se constituyen exigencias éticas necesarias en la lucha para superar el "estado actual de cosas" y construir la sociedad sobre nuevas bases. Todo ese movimiento se constituye a la praxis humana. La ética marxista es teórica y práctica. Los fines a alcanzar sólo pueden ser estimados en la relación con los medios necesarios a su realización histórica. Es por eso que la ética marxista es crítica, educativa, propositiva y utópica. 
Por lo tanto, la ética, desde el punto de vista marxista, es una investigación crítica, racional, inmanente del proceso históricosocial de producción y reproducción de las acciones humanas, en su totalidad, en el sentido de descubrir, elucidar los fundamentos materiales, sociales e históricos que condicionan y determinan sus acciones humanas concretas, efectivas. Incluso si la especificidad de la ética marxista es, también, explicar el comportamiento humano efectivo, y no reducirse a una perspectiva normativa, prescriptiva, ella no es una pura descripción de las acciones humanas, pero su análisis presenta una perspectiva de superación de toda la teoría y práctica que producen y se sostienen por la opresión y por la explotación humana, específicamente de la explotación del trabajo.

Si la especificidad de la ética es "explicar, aclarar o investigar una determinada realidad, la realidad moral, elaborando los conceptos correspondientes" (Sánchez Vázquez, 1998: 10), podemos reconocer en las diversas teorías elaboradas a lo largo de la historia, sus desdoblamientos prácticos, en el sentido de influenciar, condicionar y determinar comportamientos humanos efectivos.

\section{LA CRÍTICA DE LA ECONOMÍA POLÍTICA: ¿UN CAPÍTULO DE LA ÉTICA?}

En la Introducción a la Contribución a la crítica de la Economía Política, texto escrito en 1857, y publicado en 1939, Marx establece las condiciones del desarrollo de la economía política del siglo XVII hasta el inicio del XIX. Periodo rico y heroico en verdad, esa etapa del pensamiento económico sería marcada por una doble dinámica categorial. La misma que caracterizó el siglo XVII, y que tendría como especificidad partir de las categorías generales como la población; las clases; la división social del trabajo entre campo y ciudad; la producción y el consumo anuales; las exportaciones e importaciones, y sólo entonces llegar a las categorías más simple como la división técnica del trabajo, los intercambios y los precios.

Por el contrario, la economía política de los siglos XVIII y XIX se caracterizaría por empezar con categorías más simples - división del trabajo, dinero, valor - y de ahí partir para las categorías más generales como el Estado, los intercambios entre los Estados, el mercado mundial. Sin descuidar la importancia de la economía política practicada en el siglo XVII, Marx dirá que el método científicamente correcto es el establecido por la economía política en el siglo XVIII (MarX, 1974).

Será exactamente este el camino metodológico que Marx adoptará en su "crítica de la economía política". Dice él en el prefacio de "Para la crítica de la Economía Política", que: "Considero el sistema de la economía burguesa en este orden: capital, propiedad de la tierra, trabajo asalariado; Estado, comercio exterior, mercado mundial" (Marx, 1974: 133-134).

Se sabe que el plan de Marx quedó inconcluso. Incluso su libro, El Capital, no fue enteramente concluido. Las condiciones y circunstancias, las vicisitudes de la elaboración de la "crítica de la economía política” de Marx están magistralmente discutidas en Rosdolsky (2001, cap. 1 y 2).

Sin embargo, si Marx reconoce los méritos de la economía política clásica, y ve en ella virtudes científicas, tal hecho no significa que sus relaciones con la Economía Política clásica sean las de un seguidor de los grandes economistas. Marx es enfático, sobre todo a partir de 1857, en que su perspectiva difería, esencialmente, de la de los "economistas" por ser, dialécticamente, una crítica de la economía política, es decir, por no limitarse a ser un uso más o menos fiel del "método de la economía política", sino por reclamar un punto de vista que lo "supera", en el sentido de conservar sus elementos progresivos y despreciar lo que en aquella tradición teórica estaba definitivamente comprometido con la preservación del orden burguesa.

Marx, por tanto, responde diferentemente a cuestiones planteadas por la economía política clásica y formula cuestiones nuevas, que no formaban parte del universo conceptual de la economía política clásica. Es el caso emblemático de la teoría del valor. Marx no sólo desarrolla una teoría alternativa, y superior, del valor, en lo que se refiere a las dimensiones de sustancia y medida, como "inventa" cuestiones nuevas, en lo que se refiere al valor, que son tanto el desarrollo de la teoría de la forma del valor, el desdoblamiento categorial del valor de cambio, como la teoría del fetichismo de la mercancía que, según Rubin (1974), es la propia condición de posibilidad de formulación de la teoría del valor. 
En el texto que es su testamento teórico sobre economía política, Marx dice: "El señor Wagner olvida también que para mí no son sujetos ni el 'valor' ni el 'valor de cambio', sino que lo es solamente la mercancía” (Marx, 1977, p. 171).

Es con la crítica de la economía política de Marx, que el concepto de capital es aprehendido en todas sus diversas y complejas determinaciones. En la obra de Marx, el capital va desdoblándose en cinco grandes dimensiones: (i) como cosa, forma fenoménica necesaria de aparición histórica y lógicamente de la riqueza, como dinero, como medios de producción; (ii) como relación social, o sea, como relación de propiedad y apropiación real, como poder de comando sobre el trabajo, como relación de dominación y explotación de la fuerza de trabajo; (iii) como gramática, como lengua y como habla, como sincronía y diacronía, o sea, como un conjunto de señales - precios, interés, beneficios, rentas - que reflejando las relaciones sociales de producción establecen, mediante la regulación anárquica de la ley valor, las condiciones posibles de la reproducción material en la sociedad capitalista; (iv) como fuerza expansiva, esta dimensión es particularmente sobresaliente, hoy en la forma del extraordinario desarrollo científico y tecnológico, que no sin consecuencias negativas, se presenta como creación exclusiva de la dinámica capitalista; (v) como fuerza destructiva, en esta última personificación el capital se revela en uno de sus más característicos papeles, como implicando desempleo y destrucción ambiental, como fuerza opresiva y particularista, como fuerza social alienante.

Es con el apoyo en los descubrimientos de esas dimensiones del capital, que son los fundamentos de la crítica de la economía política, es decir, de las contradicciones que no se cancelan del capital, que ganan contornos efectivamente comprensivos tanto la denuncia de Rousseau, como los avances teóricos de la economía política clásica, como la explicitación de la insuficiencia de estos avances que están en la base de la crítica de la Economía Política, emprendida por Marx.

\section{BIBLIOGRAFÍA}

- Marx, K. (1974). Para la crítica de la Economía Política. São Paulo: Los pensadores.

- Marx, K. (1977). Glosas marginales al 'Tratado de Economía Política' de Adolph Wagner. In: DOBB, M. et al. Estudios sobre el capital, 4⿳亠丷a edición. Buenos Aires: Siglo XXI.

- Rosdolsky, R. (2001). Génesis y estructura de El capital de Karl Marx. Rio de Janeiro: Contraponto/EDUERJ.

- Rubin, I.I. (1974) Ensayos sobre la Teoría Marxista del Valor. Cuadernos PyP, n. 53. Buenos Aires: Siglo XXI.

- Sánchez Vázquez, A. (1998). Ética. Rio de Janeiro: Civilización Brasileña. 